\title{
Prevalence of helminth parasites of dogs and owners awareness about zoonotic parasites in Ambo town, central Ethiopia
}

\author{
Endrias Zewdu ${ }^{1}$, Yohannes Semahegn and Berhanu Mekibib² \\ 'Department of Veterinary Laboratory Technology, Ambo University, P.O.Box 19, \\ Ambo, Ethiopia \\ ${ }^{2}$ Department of Veterinary Medicine, Hawassa University, P.O.Box 05, Awassa, Ethio- \\ pia. Tel. +251916836763, E-mail address: bmekibib@yahoo.com \\ *Corresponding author: endriaszewdu2001@yahoo.com
}

\section{Abstract}

To determine the prevalence of gastrointestinal helminth infections of dogs in Ambo, Ethiopia, examination of 70 fecal samples and 52 necropsies were conducted from November 2007 to April 2008. The prevalence of gastrointestinal helminths was $86.54 \%$ and $52.86 \%$ as detected by post mortem and coproscopical examination, respectively. The coproscopical examination revealed $35.7 \%$ infection with Ancylostoma caninum followed by Dipylidium caninum (25.57\%), Toxocara canis (17.14\%), Strogyloides stercoralis (14.29\%) and Echinococcus granulosus (8.57\%). Mixed infections with two or more parasites were also observed (62.16\%). The study also indicates a significant difference $(p<0.05)$ in the prevalence of Toxocara canis and Dipylidium caninum between the sexes. On the other hand, $86.54 \%$ of the necropsied dogs were found positive for one or more species of adult parasites and the specific species found were Dipylidium caninum (71.15\%), Ancylostoma caninum (50\%), Strongyloides stercoralis (40.38\%), Toxocara canis (17.3\%), Echinococcus granulosus (17.3\%), Trichuris vulpis (3.8\%) and Spirocerca lupi (1.9\%). No significant difference in prevalence of the individual helminth species was noticed between the sexes and among the age groups. However, a significant difference $(p<0.05)$ in the overall infection in the area was observed between the sexes. The study further indicated that, all of the respondents were ignorant on dog parasites and health related management aspect of dogs.

Keywords: Gastrointestinal parasites, Dogs, Prevalence, Ambo, Central Ethiopia 


\section{Introduction}

Parasitism is the most encountered disease in dogs all over the world (Zelon, 2003). Regardless of the availability of effective medications to treat parasites, most parasites of dogs have highly evolved life cycles that make their elimination impossible. In addition, dogs are routinely infected with internal parasites, sometimes without apparent evidence of the infestation until it is too late. This means that a dog can have internal parasites even though the fecal sample is negative.

Gastrointestinal helminths of dogs pose serious impact both on the host and human beings. They impede the successful rearing of dogs and result in losses that are manifested by lowered resistance to infectious diseases, retarded growth, reduced work and feed efficiency and general ill health (Soulsby, 1982). Parasitized animals show a variety of symptoms, depending on the parasite species and density. These signs are attributed to intestinal obstruction, irritation, maldigestion, malabsorbtion, and protein losing gastroentropathy induced by the parasites (Dunn, 1978). Severe cases could be fatal (Barutzki and Schaper, 2003).

Moreover, since dogs live in close proximity with humans, there are zoonotic parasites that can be transmitted to humans and cause serious consequences. The transmission of zoonotic parasites could be through indirect contact with animal secretions and excretions, infected water and food, and through direct contact with the animal (Lappin, 2002). Some of the parasites like Echinococcus granulosus also involve food animals as an intermediate host and cause great economic loss through organ condemnation at the level of slaughter house (Gracey, 1986).

The prevalence of parasites considerably varies from one region to another and among the different diagnostic techniques employed (Robertson et al., 2000). Considering aspects related to public and animal health, study of the prevalence of parasitic infections in dogs should, therefore, be a continuous task, with the most relevant aim being establishment of control measures (OliveiraSequeira et al., 2002). However, in Ethiopia, very little attention was given for parasites of dogs and the works done so far on the prevalence of the different gastrointestinal parasites of dogs are scanty (Muktar Reshid, 1988; Temesgen Samuel, 1990, Shihun Shimelis, 1994; Eshetu Yimer, 2005). 
Therefore, the present study is contemplated to estimate the prevalence and identify the different species of gastrointestinal helminth parasites of dogs and to assess owners' awareness about zoonotic parasites in Ambo town.

\section{Materials and methods}

Study area and study population

The study was conducted from November 2007 to April 2008 in Ambo town, central Ethiopia.

Ambo is located $8.57^{\prime} \mathrm{N}, 37.52{ }^{\prime} \mathrm{E}, 112 \mathrm{~km}$ west of Addis Ababa at an average altitude of $2100 \mathrm{~m}$ above sea level, receiving annual rain fall of $910 \mathrm{~mm}$. It has average temperature of $18.5^{\circ} \mathrm{C}$.

Dogs of all age group and both sexes were randomly selected from confined and loose (stray) housing system. For simplicity, dogs up to 6 months of age were classified as puppies, from 6 months through one year of age were referred to as young dogs while adults were dogs above 1 year of age (Bone, 1988).

\section{Study Design}

Fecal samples were collected per rectum, using simple random sampling method, from 70 dogs and examined using floatation and sedimentation techniques (Foreyt, 1989; Chauhan and Agarwal, 2006) and the result was considered as positive when at least one parasite egg is present (Lorenzini et al., 2007). Maximum effort was made to characterize and classify the different eggs observed under $10 \mathrm{X}$ magnification to the level of genera or species (Soulsby, 1982; Hendrix, 2003).

Among stray dogs roaming in Ambo town purposely killed with strychnine sulphate baits to control rabies fifty two dogs were randomly selected and necropsically examined for presence of adult gastrointestinal tract (GIT) helminthes. The entire alimentary tract was removed and the different compartments (esophagus, stomach, small intestine, cecum and colon) were tightly ligated with gauze. The contents of the different compartments were scrapped off, along with parts of mucosa, using a spatula. The contents, collected in separate buckets, were passed through a series of graded screens (sieves) to remove fecal debris. Then the resulting sediments were placed in separate universal bottle containing equal amount of warm $10 \%$ formalin solution for further identification and classification (Georgi and Theodorides, 1980; Soulsby, 1982). 
By the time of fecal sample collection, a pre-tested semi-structured questionnaire was used to evaluate the different management practices given for dogs and owners' awareness about zoonotic canine parasites.

\section{Statistical Analysis}

Finally, the data obtained from postmortem, coprological examinations and pre-tested semi-structured questionnaire were analyzed by using Stata version 7.0 (STATA, 2001). Prevalence was calculated by dividing the number of dogs harboring any helminth parasite by the total dogs examined. The chisquare $\left(\chi^{2}\right)$ test was used to assess difference in the frequency of the nematodes between the sexes and age groups. In all the analysis, confidence level was held at $95 \%$ and statistical analyses were considered significant at $\mathrm{P} \leq 0.05$.

\section{Results}

\section{Necropsy findings}

On necropsy, $86.54 \%$ of the dogs were found positive for one or more adult parasites, namely Dipylidium caninum (71.15\%), Ancylostoma caninum (50\%), Strongyloides stercoralis $(40.38 \%)$, Toxocara canis $(17.3 \%)$, Echinococcus granulosus (17.3\%), Trichuris vulpis (3.8\%) and Spirocerca lupi (1.9\%). The necropsy examination further indicated a statistically significant difference $(P<0.05)$ in overall prevalence of GIT helminth parasites observed between the sexes of dogs (Table 1). However, there was no significant difference in the overall and respective prevalence of GIT helminth parasites as observed among the three age groups (Table 2).

Table 1: Frequency of the observed species of parasites by sexes of dogs necropsied

\begin{tabular}{lcccc}
\hline Species of parasites & \multicolumn{2}{c}{ Sex } & P value & $\chi^{2}$ value \\
\cline { 2 - 3 } & Male $(\mathrm{n}=33)$ & Female $(\mathrm{n}=19)$ & & 0.0829 \\
\hline Ancylostoma caninum & $51.51 \%$ & $47.37 \%$ & 0.77 & 0.0368 \\
Strongyloides stercoralis & $39.39 \%$ & $42.11 \%$ & 0.85 & 0.2934 \\
Toxocara canis & $15.15 \%$ & $21.05 \%$ & 0.59 & 0.1626 \\
Trichuris vulpis & $3.03 \%$ & $5.26 \%$ & 0.69 & 0.5870 \\
Spirocerca lupi & $3.03 \%$ & 0 & 0.44 & 0.1089 \\
Dipylidium caninum & $72.72 \%$ & $68.42 \%$ & 0.74 & 1.6975 \\
Echinococcus granulosus & $12.12 \%$ & $26.31 \%$ & 0.19 & 4.2465 \\
Gl Parasitism & $93.94 \%$ & $73.68 \%$ & 0.04 & \\
\hline
\end{tabular}


Table 2: Frequency of the observed species of parasites by age group of dogs necropsied

\begin{tabular}{lccccc}
\hline Species of parasites & \multicolumn{3}{c}{ Age group } & P value & $\chi^{2}$ value \\
\cline { 2 - 5 } & $\begin{array}{c}\text { Puppy } \\
(\mathrm{n}=6)\end{array}$ & $\begin{array}{c}\text { Young } \\
(\mathrm{n}=15)\end{array}$ & $\begin{array}{c}\text { Adult } \\
(\mathrm{n}=31)\end{array}$ & & \\
\hline Ancylostoma caninum & $33.3 \%$ & $40 \%$ & $58.06 \%$ & 0.36 & 2.0731 \\
Strongyloides stercoralis & $16.67 \%$ & $33.3 \%$ & $48.39 \%$ & 0.28 & 2.5363 \\
Toxocara canis & $16.67 \%$ & $26.67 \%$ & $12.90 \%$ & 0.51 & 1.3399 \\
Trichuris vulpis & 0 & 0 & $6.45 \%$ & 0.49 & 1.4090 \\
Spirocerca lupi & 0 & 0 & $3.23 \%$ & 0.71 & 0.6907 \\
Dipylidium caninum & $50 \%$ & $66.67 \%$ & $77.42 \%$ & 0.36 & 2.0482 \\
Echinococcus granulosus & 0 & $26.67 \%$ & $16.13 \%$ & 0.33 & 2.2039 \\
Gl Parasitism & $66.67 \%$ & $80 \%$ & $93.55 \%$ & 0.14 & 3.8920 \\
\hline
\end{tabular}

\section{Coproscopical findings}

During coproscopy, $52.86 \%$ of the dogs were positive for different types of parasite eggs, namely Ancylostoma caninum (35.70\%), Dipylidium caninum (25.57\%), Toxocara canis (17.14\%) Strongyloides stercoralis (14.29\%) and Echinococcus granulosus (8.57\%) (Table 5). Mixed infections with three species of helminths were more common (35.56\%) than infection with one $(24.4 \%)$, two (31.1\%), four (4.4\%) and five (4.4\%) species of helminths.

Table 3: Frequency of the observed species of parasites by sexes of dogs based on fecal examination

\begin{tabular}{lcccc}
\hline Species of parasites & \multicolumn{2}{c}{ Sex } & Pvalue & X2 value \\
\cline { 2 - 3 } & $\begin{array}{c}\text { Male } \\
(\mathrm{n}=55)\end{array}$ & $\begin{array}{c}\text { Female } \\
(\mathrm{n}=15)\end{array}$ & & \\
\hline Ancylostoma caninum & $38.18 \%$ & $26.66 \%$ & 0.41 & 0.6807 \\
Strongyloides stercoralis & $14.55 \%$ & $13.33 \%$ & 0.91 & 0.0141 \\
Toxocara canis & $21.82 \%$ & 0 & $0.047^{*}$ & 3.9498 \\
Dipylidium caninum & $20 \%$ & $46.67 \%$ & $0.036^{*}$ & 4.3875 \\
Echinococcus granulosus & $10.90 \%$ & $0 \%$ & 0.18 & 1.7898 \\
Gl Parasitism & $52.73 \%$ & $53.33 \%$ & 0.97 & 0.0017 \\
\hline
\end{tabular}

*statistically significant difference 
Endrias Zewdu, et al.

Table 4: Frequency of the observed species of parasites by age groups of dogs based on fecal examination

\begin{tabular}{lccccc}
\hline Species of parasites & \multicolumn{3}{c}{ Age group } & P value & $\chi^{2}$ value \\
\cline { 2 - 5 } & $\begin{array}{c}\text { Puppy } \\
(\mathrm{n}=4)\end{array}$ & $\begin{array}{c}\text { Young } \\
(\mathrm{n}=15)\end{array}$ & $\begin{array}{c}\text { Adult } \\
(\mathrm{n}=51)\end{array}$ & & \\
\hline Ancylostoma caninum & $0 \%$ & $46.67 \%$ & $35.29 \%$ & 0.22 & 3.0098 \\
Strongyloides stercoralis & $0 \%$ & $6.67 \%$ & $17.65 \%$ & 0.4 & 1.8484 \\
Toxocara canis & $25 \%$ & $6.67 \%$ & $19.61 \%$ & 0.46 & 1.5510 \\
Dipylidium caninum & 0 & $33.33 \%$ & $25.49 \%$ & 0.4 & 1.8418 \\
Echinococcus granulosus & 0 & $0 \%$ & $11.76 \%$ & 0.3 & 2.4449 \\
Gl Parasitism & $25 \%$ & $60 \%$ & $52.94 \%$ & 0.46 & 1.5530 \\
\hline
\end{tabular}

The result obtained from necropsy examination and fecal examination (coproscopy) revealed that the prevalence of helminth parasite in male and female were $93.94 \%, 73.68 \%$ and $52.73 \%, 53.33 \%$, respectively (Tables 1 and 3). Similarly, the prevalence of helminth parasite in puppies, young and adult dogs by employing necropsy and coproscopy were $66.67 \%, 80 \%, 93.55 \%$ and $25 \%, 60 \%$, $52.94 \%$, respectively (Tables 2 and 4). There was a statistically significant difference $(P<0.05)$ in the prevalence of Toxocara canis and Dipylidium caninum between the sexes as examined by coproscopy (Table 3 ). There was also a significant difference $(P<0.05)$ in the overall prevalence of $\mathrm{Gl}$ parasites and Strongyloides stercoralis as detected by necropsy examination and coproscopy (Table 5).

Table 5. The prevalence of the observed species of parasites by the techniques employed

\begin{tabular}{lccc}
\hline Species of parasites & \multicolumn{2}{c}{ Technique } & P value \\
\cline { 2 - 3 } & $\begin{array}{c}\text { Necropsy } \\
(\mathrm{n}=52)\end{array}$ & $\begin{array}{c}\text { Coproscopy } \\
(\mathrm{n}=70)\end{array}$ & \\
\hline Ancylostoma caninum & $50 \%$ & $35.71 \%$ & 0.114 \\
Strongyloides stercoralis & $40.38 \%$ & $14.29 \%$ & $0.001^{*}$ \\
Toxocara canis & $17.31 \%$ & $17.14 \%$ & 0.98 \\
Trichuris vulpis & $3.85 \%$ & 0 & 0.098 \\
Spirocerca lupi & $1.92 \%$ & 0 & 0.25 \\
Dipylidium caninum & $71.15 \%$ & $25.71 \%$ & $0.00^{*}$ \\
Echinococcus granulosus & $17.31 \%$ & $8.57 \%$ & 0.135 \\
Gl Parasitism & $86.54 \%$ & $52.86 \%$ & $0.00^{*}$ \\
\hline
\end{tabular}

* Statistically significant 
Management practice and awareness of dog owners

Out of 70 respondents, 6 of them (8.6\%) were keeping dogs as companionship, whereas $34(48.6 \%)$ and 30 (42.9\%) for guardians and both, respectively. Regarding the keepings of dogs, $55(78.57 \%)$ of the dogs were free (both indoor and outdoor system) and only 15 (12.43\%) were kept confined indoor.

In the area, dogs with a separate house or kennel were found only in 18 households $(25.7 \%)$ of which only $46.6 \%$ of the kennels or dog houses were cleaned at an interval of 1 or 2 months. None of the individuals cleaning the kennels were taking the necessary precautions.

Only $8(11.43 \%)$ of the households disposed dogs' feces in their toilets. Even though some of the dogs $(n=15)$ are confined within their home or compound during the day, the dogs were released during evening time and hence shade their feces everywhere.

Regarding dogs feeding practice of the area, raw animal products and/or household leftover were the only feed given for the dogs. There is no tendency of cooking animal products intentionally to feed dogs.

Only $44.3 \%$ of the owners in the area have awareness about the role of dogs in transmitting diseases to human beings. Unfortunately, the awareness was only for rabies; none of them had awareness of canine zoonotic parasites. According to the respondents, the main reason that deters them from using antihelminthics for dogs was lack of awareness about the availability of drugs and the possibility of treating dogs with antihelminthics.

Information obtained from the animal health workers in the area revealed that dogs were brought to the clinic mainly due to infectious diseases, especially rabies and canine distemper. Dogs never came for antihelminthic treatment.

\section{Discussion}

Among the total of 52 dogs necropsied 45 (86.54\%) were found harboring one or more species of helminth parasites. The high prevalence observed in the present study was in agreement with studies from Cameroon (Komatangi, 2005), South Africa (Minnaar et al., 2002) and Nigeria (Dada et al., 1979; Anene et al., 1995), who reported prevalence of $88.5 \%, 76 \%, 97.8 \%$ and $68.5 \%$, respectively. Previous studies conducted in Ethiopia also showed a higher level of infection in homeless dogs, which is $98.36 \%$ and $95 \%$ in Debre Zeit (Shihun Shimelis, 1994; Yacob et al., 2007), 100\% in Dire Dawa and Eastern Hararge as well as 
Wollaita (Muktar Reshid, 1988; Temesgen Samuel, 1990). The difference in the prevalence between our study and these authors could be attributed to geographical areas and / or health care and animal management practice followed. Compared to fully indoor kept dogs, the free roaming nature of dogs in our study might have exposed them to widespread natural infection. Moreover, it is difficult to monitor and implement parasitic disease control measures like regular deworming in such group of dogs. Although the exact role of dog in the transmission of parasites to humans in the study area has not been clearly determined (Eguia-Aguilar et al., 2005) they may have serious public health implication by acting as important source of infection.

In the present study infection with more than one helminth parasite (polyparasitism) is common. Concurrent infection with three different species of helminths in same dog was more common $(35.56 \%)$ than infection with one (24.4\%), two (31.1\%), four (4.4\%) and five (4.4\%) species of helminths. Similar finding was also reported by Traub et al. (2002). Higher incidences of concurrent infections with more than one species of helminths (75.6\%) were also reported previously in Ethiopia (Muktar Reshid, 1988; Shihun Shimelis, 1994). On the other hand single parasite infection was reported in studies conducted abroad (Anene et al., 1995; Bugg et al., 1999; Papazahariadou et al., 2007). This difference may be attributed to the level of awareness about dog parasite, regular deworming, housing and other management activities practiced in these areas.

The most prevalent adult helminth observed in the present study was Dipylidium caninum $(71.15 \%)$. This result was in agreement with the result in South Africa (Minnaar et al., 2002). However, Ancylostoma caninum was the most prevalent helminth in those studies conducted in Wollaita (Muktar Reshid, 1988), in Dire Dawa and Eastern Hararge (Temesgen Samuel, 1990), and in Debre Zeit (Shihun Shimelis, 1994). The prevalence of Dipylidium caninum in the present study (71.15\%) was higher than the report from Wollaita (Mukar Reshid, 1988), South Africa (Minnaar et al., 2002) and Debre Zeit (Shihun Shimelis, 1994), with prevalence of $32.38 \%, 44 \%$ and $47.54 \%$, respectively. However, higher prevalence was reported by Dada et al. (1979) in Zaria, Nigeria (97.8\%) and Temesgen Samuel (1990) in Dire Dawa and Eastern Hararge (83\%).

The prevalence of Toxocara canis was found lower in the present study (17.3\%) compared with similar studies carried out in Punjab, Pakistan (Maqbool et al., 1998), Northeastern India (Traub et al., 2002), Nsukka area, Nigeria (Anene et 
al., 1995), South Africa (Minnaar et al., 2002), and Debre Zeit (Shihun Shimelis, 1994). Low prevalence of T. canis observed in the present study may be partly explained by the small number of puppies sampled. Otherwise, most Ascarids have been found mainly in dogs younger than one year (MartinezMoreno et al., 2006).

The prevalence of Echinococcus granulosus in the present study (17.3\%) was coherent to the record in Addis Ababa (Eshetu Yimer et al., 2005). Previous investigation in Ethiopia have shown a higher prevalence in Wollaita (22.3\%) (Muktar Reshid, 1988) and in Dire Dawa and Eastern Hararge (50\%) (Temesgen Samuel, 1990). However, Shihun Shimelis (1994) indicated that $9.84 \%$ of the dogs examined were harboring E. granulosus. Young and adult dogs were more affected and this may be attributed to their roaming habits and acclimatization to flesh and offals. There is a widespread backyard slaughter of animals throughout the country, for example Kiphorir (1998) estimated that in Ethiopia, $83 \%$ of the off-take in cattle, and $94 \%$ of the off-take in sheep and goats is by backyard slaughter. Together with large stray dog population around poorly supervised abattoirs, these animals constitute the principal definitive host reservoir of E. granulosus.

The prevalence of Tricuris vulpis in the present study (1.67\%) was lower than the $3 \%$ incidence observed in Debre Zeit (Yacob Hailu et al., 2007), 13.9\% and 3.6\% in Nigeria (Dada et al., 1979 and Anene et al., 1995, respectively), and 9.6\% in Northern Greece (Papazahariadou et al., 2007). However, it was found consistent with a study in Southern Spain (Martinez-Moreno et al., 2006).

Spirocerca lupi was encountered only in one dog (1.9\%) at necropsy and its eggs were not found in any of the fecal samples examined. On necropsy based studies, higher prevalence of S. lupi was recorded in Debre Zeit by Shihun Shimelis (1994) and Yacob et al. (2007). They reported $32.79 \%$ and $23.5 \%$, respectively. A prevalence of $12.7 \%$ was recorded in South Africa (Minnaar et al., 2002).

Unlike the postmortem results of this study, the most prevalent parasite found by coproscopy was Ancylostoma caninum and infection with three species was more common $(28.7 \%)$ than infection with two $(27.7 \%)$ or one $(10.9 \%)$. This contradicts the findings of Traub et al. (2002) who reported that the most prevalent infection (32.83\%) being by two species; and (Komatangi, 2005) and Bugg et al. (1999) that reported no dog was concurrently infected with more than one species of helminths. 
The prevalence of Dipylidium caninum in fecal samples was $25.57 \%$ which is higher than the reports of Collins (1981), Anene et al. (1995), Minnaar et al. (2002), Komatangi (2005) and Papazahariadou et al. (2007). Very low prevalence of D. caninum occurred in European countries such as Greece (Papazahariadou et al., 2007), Spain (Martinez-Moreno et al., 2006), Finland and other Nordic countries (Pullola et al., 2006) as well as Australia (Bugg et al., 1999). The routine use of anthelminthics, particularly in puppies is the most likely cause for the reduced prevalence of gastrointestinal helminthes in such countries (Robertson et al., 1991). There was a significant prevalence difference $(p<0.05)$ between the sexes, with $46.67 \%$ female and $20 \%$ male dogs harboring the eggs of Dipylidium caninum. This result may partially be explained by the lower number of female dogs examined.

The prevalence of Echinococcus granulosus in the coproscopical study $(8.57 \%)$ was lower than the $14.6 \%$ incidence recorded in Addis Ababa (Eshetu Yimer et al., 2005). According to the present study, $10.9 \%$ of the male dogs were infected while no females were infected. This may be due to the lower number of females $(n=15)$ than males $(n=55)$ examined. Only adults were infected with Echinococcus granulosus and this may be attributed to their roaming characters. The eggs of Taenia spp. could not be distinguished using microscopy alone. It is likely that a significant underestimation of the prevalence of this family has been observed in this study due to the erratic nature of proglottid and egg shedding by these parasites.

The absence of Spirocerca lupi eggs in fecal samples may be due to the floatation medium (sodium chloride) used in the present study. There are other floatation medias with higher specific gravities (such as saturated solutions of magnesium sulphate or sodium nitrate) which, when used with the fecal floatation method, will yield higher numbers of eggs and therefore prove to be more sensitive (Sloss et al., 1994).

Lower prevalence of Strongyloides stercoralis was encountered in fecal samples (14.29\%) than in postmortem samples (40.38\%). The lower prevalence of the eggs of this parasite observed in the current study may be attributed to the type of fecal samples collected for examination. During the study period, fecal samples collected and preserved (using $5 \%$ formalin) by dog owners as per instructions provided earlier were received for coproscopic examination the following day. However, S. stercoralis could only be examined in fresh samples. 
The prevalence recorded during post mortem and coproscopical examinations showed significant differences, indicating a higher power of detection by the former. This could also be due to the fact that coproscopical examination may not detect the immature parasites, which are unable to lay eggs.

Regarding the management practice and awareness of dog owners, most dogs were allowed to roam freely and were observed to defecate in areas other than their immediate surrounding. Moreover, the authors had a chance to see animal cadavers thrown in the villages and on the street where dogs commonly feed on. It is, therefore, certain that dogs are acting as disseminators of parasite eggs and suitable reservoir of adult parasite thereby increasing the net exposure of infective stages in contact with the human population and other animals.

Except for little awareness on rabies, all the respondents were unaware of the potential risk of canine parasitic zoonoses. In line with the findings of the present study, a similar condition was reported in Northeastern India (Traub et al., 2002). However, high level of awareness was recorded by Bugg et al. (1999) from Perth, Australia. These differences might be associated with veterinary facilities and availability of adequate information in different mass Medias in developed nations. Poor management practice and level of awareness of dog owners about dog parasites and associated risk, in addition to lack of veterinary attention, could exacerbate risk of transmission of canine parasitic zoonoses to human community.

All of the respondents have not ever came across any internal parasites in their dogs and this may be attributed to the loose type of dog keeping practice in the area or due to the lack of awareness on the clinical manifestations and morphology of the common intestinal parasites of dogs

As a general principle of parasitic disease control scheme, the life cycle of these parasites should be broken either by regular deworming of dogs or inhibiting dogs from having access to offal's containing or contaminated with intermediate stages of dog parasites. Awareness should be created for dog owners and other community regarding the husbandry of dogs, potential role of dogs in the transmission of zoonotic diseases, control and prevention strategies of parasitic diseases and health and welfare of dogs. Control of stray dog population should be carried out by the provincial veterinary structures. 


\section{Acknowledgments}

The authors would like to thank Hawassa University and Ambo University for their financial support. Dog owners of Ambo town are highly acknowledged for their cooperation during the study.

\section{References}

Anene, B. M., Nnaji, T. O. and Chime, A. B., 1995. Internal parasitic infections of dogs in the Nsukka area of Enugu State, Nigeria. Prev. Vet. Med. 27, 89-94.

Barutzki, D. and Schaper, R., 2003. Endoparasites in dogs and cats in Germany 1999 2002. Parasitol. Res. 90, 5148-5150.

Bone, J. F. (1988): Animal Anatomy and Physiology. Third edition, Prentice-Hall, Inc., Newjersy, USA.

Bugg, R.J., Robertson, I.D., Elliot, A.D. and Thompson, R.C.A. 1999. Gastrointestinal parasites of urban dogs in Perth, Australia. Vet. J., 157, 295-301.

Chauhan, R.S. and Agarwal, D.K. 2006. Textbook of Veterinary Clinical and Laboratory Diagnosis, $2^{\text {nd }}$ edition, Jaypee Brothers Medical Publishers, New Delhi, India.

Collins, G.H., 1981. A survey of gastrointestinal helminths of dogs in New Zealand. New Zealand Vet. J., 29, 163-164.

Dada, B.J.O., Adegboye, D.S., Mohammed, A.N., 1979. A survey of gastrointestinal helminth parasites of stray dogs in Zaria, Nigeria. Vet. Rec., 104, 145-146.

Dunn, A., 1978. Veterinary Helminthology, William Heinemann Medical Books Ltd, London.

Eguia-Aguilar, P., Cruz-Reyes, A., Martinez-Maya, J.J., 2005. Ecological analysis and description of the intestinal helminths present in dogs in Mexico City. Vet. Parasitol., 127, 139-146.

Foreyt, W. J., 1989. Veterinary Parasitology Reference Manual, $5^{\text {th }}$ edition, Blackwell Publishing, London.

Georgi, J. R., Theodorides, V. J., 1980. Parasitology for Veterinarians, Third edition, W.B. Sounders Co., Philadelphia.

Gracey, J.F., 1986. Meat Hygiene $8^{\text {th }}$ edition, Baillere Tindall, London 
Hailu, Y., Ayele, T., Fikru, R. and Basu, A.K., 2007. Gastrointestinal nematodes in dogs from Debre Zeit, Ethiopia. Vet. Parasitol., 148, 144-148.

Hendrix, C.M., 2003. Laboratory Procedures for Veterinary Technicians, 4th edition, Mosby Inc., USA

Kiphorir, K.P., 1998. Prevalence and strain difference of Echinococcus granulosus in some selected sites of Ethiopia, MSc thesis, Addis Ababa University.

Komatangi, M.C., 2005. Prevalence of gastrointestinal helminths of dogs in Dschang, Cameroon. J. Cam. Acad. Sc., 5, 11-14.

Lappin, M.R., 2002. Pet Ownership by Immunocompromised People. Bayer Zoonosis Symposium, N. Am. Vet. Conf., 24, 16-25.

Lorenzini, G., Tasca, T., and De Carli, G.A., 2007. Prevalence of intestinal parasites in dogs and cats under veterinary care in Porto Alegre, Rio Grande do Sul, Brazil. Braz J vet Res anim Sci., 44, 137-145

Maqbool, A., Raza, S.H., Hayat, C.S. and Mohammad, Shafiq, M., 1998. Prevalence and chemotherapy of toxocariasis in the dog in Faisalabad (Punjab), Pakistan. Vet. Arch., 68, 121-125.

Martinez-Moreno, F.J., Hernandez, S., Lopez-Cobos, E., Becerra, C. and Acosta, I., 2006. Estimation of canine intestinal parasites in Cordoba (Spain) and their risk to public health. Vet. Parasitol., 143, 7-13.

Minnaar, W.N., Krecek, R.C. and Fourie, L.J., 2002. Helminths from a peri-urban resource limited community in Free State Province, South Africa. Vet. Parasitol., 107, 343-349.

Reshid, M., 1988. Preliminary survey of gastrointestinal helminths in dogs, Cysticercosis tenuicollis in sheep and goats, hydatidosis in sheep, goats and cattle at Wollaita Awraja. DVM thesis, Faculty of Veterinary Medicine, Addis Ababa University.

Oliveira-Sequeira, T.C., Amarante, A.F., Ferrari, T.B., Nunes, L.C. 2002. Prevalence of intestinal parasites in dogs from Sao Paulo State, Brazil. Vet. Parasitol., 103, 19-27.

Papazahariadou M, Founta A, Papadoupaulos E, Chliounakis S, Antoniadou K and Theodorides Y. 2007. Gastrointestinal parasites of shepherd and hunting dogs in Serres Prefecture, Northern Greece. Vet. Parasitol., 148, 170-173. 
Pullola, T., Vierimaa, J., Saari, S. and Sukura, A., 2006. Canine intestinal helminths in Finland: Prevalence, risk factors and endoparasite control practices. Vet. Parasitol., 140, 321-326.

Robertson, I.D., Irwin, P.J., Lymbry, A.J. and Thompson, R.C.A., 2000. The role of companion animals in the emergence of parasitic zoonosis. Int. J. Parasitol., 30, 13691377.

Shimelis, S., 1994. Prevalence of gastrointestinal helminths of dogs in Debre Zeit, Ethiopia. A DVM thesis. Faculty of Veterinary Medicine, Addis Ababa University.

Sloss, M.W., Kemp, R.L., Zajac, A.M., 1994. Veterinary Clinical Parasitology, $6^{\text {th }}$ edition, lowa State University Press, lowa.

Soulsby, E.J.L., 1982. Helminths, Arthropods and Protozoa of Domesticated Animals. $7^{\text {th }}$ edition, Bailliere Tindall, London.

STATA, 2001. Stata Statistical Software, State Corporation, Texas, 77845, USA.

Samuel, T., 1990. The external and GIT helminth parasites of dogs in Dire Dawa and eastern Hararge. A DVM thesis. Faculty of Veterinary Medicine, Addis Ababa University.

Traub, R.J., Robertson, I.D., Irwin, P., Mencke, N. and Thompson, A., 2002. The role of dogs in transmission of gastrointestinal parasites in a remote tea-growing community in Northeastern India. Am. J. Med. Hyg., 67, 539-545.

Yimer, E., Ekoro, B., Tilhun, W., Badeg, Z. and Abebe, B., 2005. Prevalence of hydatidosis in animals slauthered at the Addis Ababa abattoir and dog Echinococcosis in Addis ababa city. Eth. Vet. J., 9, 151-154.

Zelon, D.B., 2003. Dogs, Humans and Gastrointestinal Parasites: Unraveling Epidemiological and Zoonotic Relationships in an endemic Tea-Growing Community in Northeast India. [http://www.lookd/dogs] 